\title{
Apical extrusion of intracanal biofilm after root canal preparation using Revo-S, Twisted File Adaptive, One Shape New Generation, ProTaper Next, and K3XF instrumentation systems
}

\author{
Recai Zan, ${ }^{1}$ Hüseyin Sinan Topçuoğlu, ${ }^{2}$ Tutku Tunç, ${ }^{3}$ Senem Gökçen Yiğit Özer, ${ }^{4}$ \\ İhsan Hubbezoğlu, ${ }^{5}$ Gizem Kutlu' \\ 'Department of Endodontics, Cumhuriyet University Faculty of Dentistry, Sivas, Turkey \\ ${ }^{2}$ Department of Endodontics, Erciyes University Faculty of Dentistry, Kayseri, Turkey \\ ${ }^{3}$ Department of Microbiology, Cumhuriyet University Faculty of Medicine, Sivas, Turkey \\ ${ }^{4}$ Department of Endodontics, Adnan Menderes University Faculty of Dentistry, Aydın, Turkey \\ ${ }^{5}$ Department of Restorative Dentistry, Cumhuriyet University Faculty of Dentistry, Sivas, Turkey
}

\begin{abstract}
Objective: To evaluate the amount of bacteria extruded apically during instrumentation using different nickel titanium (NiTi) rotary instruments.

Methods: Eighty extracted single-rooted human mandibular premolar teeth were inoculated with $E$. faecalis to obtain biofilm formation and the re-inoculation procedure was performed on the first, fourth, seventh and tenth days. The infected root canals were prepared using Revo-S (RS), Twisted File Adaptive (TFA), One Shape New Generation (OSNG), ProTaper Next (PTN), and K3XF instrumentation systems. The amount of apially extruded bacteria was incubated in brain heart infusion agar and it was measured in colony forming units per milliliter. Data were analyzed using the one-way analysis of variance (ANOVA) and Tukey post-hoc tests.
\end{abstract}

Results: The RS group caused more bacterial extrusion compared to other groups $(p<0.05)$. Although the OSNG and K3XF caused the less amount of bacteria extrusion than TFA and PTN groups $(p<0.05)$, there was no statistically significant difference between OSNG and K3XF ( $p>0.05)$. TFA extruded more bacteria compared to the PTN group $(p<0.05)$.

Conclusion: All NiTi instrumentation systems were associated with apical extrusion of biofilm. OSNG and K3XF appear to be safer instruments in terms of biofilm extrusion compared to other instruments. The apically extruded bacteria may vary according to the instrument metallurgy, kinematics and design.

Keywords: Apical extrusion; biofilm; rotary files.

$\mathrm{R}$ oot canal preparation is one of main stages of endodontic treatment. Moreover, undesirable results may occur during this important stage. One of the crucial issues which might occur during preparation is the extrusion of bacteria, irrigants, necrotic tissues, and filling materials into periapical tissues, leading to periapical inflammation and postoperative flare-ups. ${ }^{[1]}$ Specifically, more severe tissue reactions are observed when instrumentation is not

Correspondence: Dr. Recai Zan. Cumhuriyet Üniversitesi Diş Hekimliği Fakültesi,

Endodonti Anabilim Dalı, Sivas, Turkey.

Tel: +90 346 - 2191010 / 2764 e-mail: drrecaizan@hotmail.com

Submitted: April 26, 2016 Accepted: April 26, 2016

(C)2016 Turkish Endodontic Society

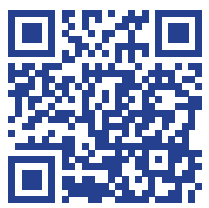


limited within the root canal system. ${ }^{[2]}$ Furthermore, the microbial colonies extruded from the root canal system to the periradicular tissues are one of the most significant causes of inter-appointment flare-ups. ${ }^{[1]}$ Therefore, it is necessary to minimize the amount of apically extruded material to prevent postoperative reactions.

Microorganisms and debris remaining within the root canal system play a significant role in the outcome of endodontic treatment. Microbiological research has recently focused on resistant biofilms to elucidate the real causes of failed endodontic treatments. A commonly used definition of a biofilm is a "microbially derived sessile community characterized by cells that are irreversibly attached to a substratum or interface or to each other". In a biofilm, cell densities are significantly higher than in a planktonic culture. ${ }^{[3]}$ Biofilm is the community of microorganisms that may be isolated from infected root canals. Biofilms have special characteristics such as the difficulty of elimination from root canals. As they are commonly existing structures in root canals contributing to the failure of endodontic treatment, we used biofilms similar to other recent studies. ${ }^{[4,5]}$

Various researchers emphasized the importance of extrusion of infected debris that may be incurred during the instrumentation with different preparation techniques and instruments, even when preparation is maintained short of the apical foramen. ${ }^{[6-10]}$ The amount of debris extrusion may differ according to the preparation techniques and the design of the file systems. ${ }^{[10]}$

Revo-S (RS; Micro-Mega, Besancon, France) system was developed with a distinctive asymmetric cross-section intended to decrease the stress on the instrument. ${ }^{[11]}$ Recently, new generations of nickel titanium (NiTi) rotary instruments with higher flexibility and greater cutting efficiency have been introduced. The Twisted File Adaptive (TFA; Sybron Endo, Amersfoort, The Netherlands) represents one of the most advanced endodontic NiTi rotary files in the market. It has 3 unique design features: the $\mathrm{R}$-phase heat treatment, twisting of the metal, and special surface conditioning. These features specifically contribute to the prevention of extrusion beyond the apical fora$\operatorname{men}^{[12,13]}$ and provide greater flexibility. ${ }^{[14]}$

Another recently introduced root canal single file preparation system is One Shape New Generation (OSGN; Micro Méga). The OSNG file has an asymmetric cross-sectional geometry and longer pitch that ensure an optimal and improved cutting action in three zones of the root canal. ${ }^{[13]}$ This design of OSNG file may increase the available volume for upward debris elimination and downward movement may offer effective apical progression. ${ }^{[14]}$
$\mathrm{K} 3 \mathrm{XF}$ (SybronEndo) is the next generation of $\mathrm{K} 3$ (SybronEndo) instrumentation system. The manufacturer claims that K3XF provides clinicians with the basic features of the original $\mathrm{K} 3$ plus an extraordinary new level of flexibility and resistance to cyclic fatigue with the proprietary R-phase technology. These features of K3XF file were found to be effective in decreasing the extrusion of

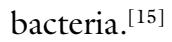

The ProTaper Next instruments (PTN; Dentsply Maillefer, Ballaigues, Switzerland) are made from M-wire that is claimed to improve file flexibility and resistance to cyclic fatigue whilst retaining cutting efficiency. ${ }^{[16,17]}$ These new generation instruments incorporate a snake-like swaggering movement as the file advances into the root canal. This design of file may help to result in less debris extrusion from the apical constriction. A survey of the literature shows that few studies have evaluated the efficacy of these NiTi systems on extrusion of intracanal biofilms.

In light of this information, the purpose of current study was to investigate the extrusion of biofilms during instrumentation of root canals using RS, TFA, K3XF, PTN, and OSNG nickel titanium (NiTi) rotary systems.

\section{Materials and methods}

\section{Tooth selection and preparation}

The study was approved by the Local Ethics Committee on Human Research of Cumhuriyet University (2014-10$21)$. Eigthy extracted human single-rooted mandibular premolar teeth were used for this study. Criteria for tooth selection included a single root canal, no visible crown and root caries, fractures, or cracks, no signs of internal or external resorption or calcification, a completely formed apex, and a curvature $<5^{\circ}$. The teeth were cleaned of debris and soft tissue remnants and were stored in physiological saline solution at $+4^{\circ} \mathrm{C}$ until usage.

Endodontic access cavities were prepared using diamond (Endo Access Bur; Dentsply Maillefer) with a highspeed hand piece under water cooling. The pulp chambers were accessed and the canal patency was then established with a size $10 \mathrm{~K}$-file (Dentsply Maillefer). Canals that were patent to greater than International Standards Organization (ISO) size 15 were discarded ${ }^{[18]}$ and eighty teeth were finally selected. To ensure standardization and obtain a reference point, both cusp edges of each tooth were flattened and all teeth was standardized to $19 \mathrm{~mm}$. A size 10 K-file (Dentsply Maillefer) was introduced into the canal until the file tip was observed at the apical foramen. The working length (WL) was determined by subtracting 1 $\mathrm{mm}$ from this measurement. 


\section{Test apparatus}

A previously described method was used ${ }^{[19,20]}$ for the experimental evaluation. The vials with rubber stoppers were adjusted for use by using a heated instrument to create a hole through the center. A hole was created on each stopper and a $25-\mathrm{G}$ needle was inserted alongside the stopper to equalize the air pressure inside and outside the tubes. Then, each stopper with the tooth and the needle was attached to its Eppendorf tube, and the tubes were fitted into vials. The entire apparatus was handled only by the outer vial. In no case was the inner Eppendorf tube touched with fingers. All vials were covered with aluminum leaf to prevent the operator from viewing debris extrusion during the instrumentation phase. All teeth were coded and then randomly assigned to 5 groups of 16 specimens each.

The entire model system was sterilized in ethylene oxide gas for a 12 -h cycle using the anprolene and $74^{\circ} \mathrm{C}$ gas sterilizer (Andersen Products Inc., Haw River, NC, USA).

\section{Contamination with $E$. faecalis Biofilm}

E. faecalis (ATCC 29212) strains were cultured on blood agar (Brain-heart infusion agar, Acumedia Manufactures, Inc., Lansing, Michigan, USA) and were incubated at $37^{\circ} \mathrm{C}$ for $24 \mathrm{~h}$. Before each experiment, 0.5 McFarland turbidity was set with a kristalspecTM device. Then subculturing was performed on Trypticase soy broth (Detroit, Michigan, USA) and the strains were incubated aerobically at $37^{\circ} \mathrm{C}$ for $24 \mathrm{~h}$. The turbidity of E. faecalis culture was adjusted to No. 0.5 Mc Farland Standard. The value of $10 \mu \mathrm{l}$ of bacterial suspension (final concentration of about $1.5 \times 10^{8}$ ) were transferred to the mechanically expanded lumen of the root canal using a sterile micropipette except 10 canals to be used as negative controls and then kept at $37^{\circ} \mathrm{C}$ for $24 \mathrm{~h}$. The access cavities were then sealed with Cavit ${ }^{\mathrm{TM}}$ temporary filling material (3M ESPE, Dental products, USA). All samples were stored at $37^{\circ} \mathrm{C}$ for 10 days in a humid atmosphere and the re inoculation procedure was repeated every $72 \mathrm{~h}$ with fresh culture at first, fourth, seventh and tenth days. The obtained biofilm is shown in Figure 1.

\section{Experimental groups and instrumentation procedures}

One operator, using aseptic techniques performed the canal preparation and sampling procedures on each specimen under a Class I laminar airflow cabinet to prevent airborne bacterial contamination. Engine-driven instruments were used according to the manufacturer's instructions. The instrumentation sequences used were as follows:

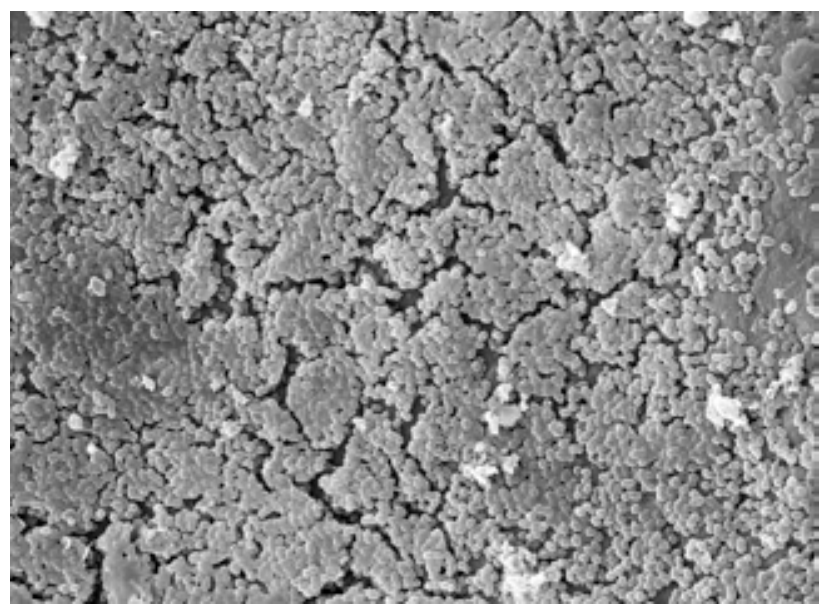

Fig. 1. Stereomicroscopic image of developed E. faecalis biofilm in a root canal.

\section{Revo-S (RS) Group}

The RS files (Micro-Mega, Besancon, France) were used with a torque-controlled electric motor (VDW Silver; VDW GmbH, Munich, Germany) at a rotational speed of $300 \mathrm{rpm}$ and $0.6 \mathrm{Ncm}$ torque. SCl (size 25, .06) was used to enlarge the coronal two-thirds of the root canal. Then, SC2 (size 25, .04 taper), SU (size 25, .06 taper), AS30 (size 30, .06 taper), and AS35 (size 35, .06 taper) were used at the WL.

\section{Twisted File Adaptive (TFA) Group}

TFA (SybronEndo, Orange, CA, USA) instruments were used with the TFA program of their motor in a sequence of MLl (size 25, .08) and ML2 (size 35, .06). MLl and ML2 instruments were taken carefully into the canal until the WL was achieved, using a Sybron Elements motor (SybronEndo, Orange, CA, USA) selected in the adaptive motion. Each instrument in TFA technique was moved in apical direction using an in-and-out motion of about 3 $\mathrm{mm}$ in amplitude with a light apical pressure.

\section{One Shape New Generation (OSNG) Group}

A 'new generation' OSNG file (Micro-Mega, Besancon, France) (size 25, .06) was used with in-and-out movements without pressure at a rotational speed of $400 \mathrm{rpm}$ and $2 \mathrm{Ncm}$ torque at the WL, using a torque-controlled electric motor (VDW Silver; VDW). Then, OSNG Apical 1 (size 30, .06 taper) and 2 (size 37, .06 taper) were used at a rotational speed of $400 \mathrm{rpm}$ and $1 \mathrm{Ncm}$ torque at the WL.

\section{K3XF Group}

$\mathrm{K} 3 \mathrm{XF}$ instruments were used with a gentle in-and-out 
motion at a rotational speed of $400 \mathrm{rpm}$ using a Sybron Elements motor (SybronEndo, Orange, CA, USA). K3XF orifice opener file (size $25, .10$ ) was used one half of the WL. Then, the other K3XF files (size 25, .04, size 25, .06 , size 30, .06 taper, and size 35, .06 taper) were used at the WL.

\section{ProTaper Next (PTN) Group}

PTN instruments were used with a gentle in and out brushing motion at a speed of 300rpm with light apical pressure. For optimum usage, torque control device was at $2 \mathrm{~N} \mathrm{~cm}^{-1}$. All instruments were used to full working length. The instrumentation sequence was used as follows: X1 (size 17, 0.4 taper), X2 (size 26, 0.6 taper), X3 (size 30, 0.7 taper), and X4 (size 40, 0.6 taper) instruments at the WL.

All systems were used in a sequence of the file recommended by the manufacturer for each specific system used. The total amount of distilled water solution used for each instrumentation system was $10 \mathrm{ml}$; by using a syringe and a 29-gauge double-side port NaviTip irrigation needle (Ultradent, South Jordan, UT, USA). The irrigation needle was placed as deep as possible into the canal without resistance until $1 \mathrm{~mm}$ short of the WL. The flutes of the instrument were cleaned after each removal from the root canal of the instrument. Canal patency was checked using a size $10 \mathrm{~K}$ - file. All root canal preparations were completed by a single operator.

\section{Evaluation of apically extruded bacterial}

Evaluation was performed by a second examiner who was blinded to group assignment. Paper points were placed in the root canals before instrumentation to control the evaluation of biofilm formation. The extruded bacteria were detected in the vial. Then, the CFUs incubated in brain heart infusion agar were calculated.

\section{Statistical analysis}

The variation data for the irrigation solutions were analyzed using SPSS statistical software (SPSS 22.0, SPSS Inc., Chicago, USA). The data were subjected to statistical analysis among the five different groups using one-way ANOVA. Tukey's post-hoc test was applied when significant differences appeared, in order to examine pairwise differences at a significance level of 0.05 .

\section{Results}

The mean and standard deviations of apically bacteria extruded in each group is shown in Table 1. The results of the one-way ANOVA test indicated that RS group extruded significantly more bacteria than all other groups $(\mathrm{p}<0.05)$. TFA group caused statistically more bacteria extrusion significant differences when compared with OSNG, K3XF, and PTN $(\mathrm{p}<0.05)$. Although PTN produced significantly less bacteria extrusion than RS and TFA, it caused more bacteria than OSNG and K3XF $(\mathrm{p}<0.05)$. There was no statistically significant difference between OSNG and KXF groups $(\mathrm{p}>0.05)$.

\section{Discussion}

Various root canal instruments and irrigation systems have been produced and assessed in terms of their debris and microorganisms extrusion. Because the apical extrusion of debris has a deleterious effect on the prognosis of root canal treatment. Seltzer, et al. ${ }^{[2]}$ indicated that a quiescent chronic inflammatory periapical lesion may give a violent

Table 1. Mean (Standard Deviation) together with their statistical comparisons, minimum and maximum values were obtained from all groups

\begin{tabular}{|c|c|c|c|}
\hline Groups & $\begin{array}{l}\text { Mean (SD) } \\
\left(\text { CFU } \mathrm{mL}^{-1}\right)\end{array}$ & $\begin{array}{l}\text { Minimum } \\
\left(\mathrm{CFU} \mathrm{mL}^{-1}\right)\end{array}$ & $\begin{array}{l}\text { Maximum } \\
(\text { (CFU mL-1) }\end{array}$ \\
\hline Group 1 & $27.80(4.98)$ & 20.00 & 36.00 \\
\hline \multicolumn{4}{|l|}{ Revo-S } \\
\hline Group 2 & $23.80(3.24)$ & 18.00 & 30.00 \\
\hline \multicolumn{4}{|l|}{ Twisted File } \\
\hline Group 3 & $16.35(2.94)^{\mathrm{a}}$ & 13.00 & 26.00 \\
\hline \multicolumn{4}{|c|}{ One-Shape New Generation } \\
\hline Group 4 & $17.15(3.41)^{\mathrm{a}}$ & 10.00 & 23.00 \\
\hline \multicolumn{4}{|l|}{$\mathrm{K} 3 \times \mathrm{f}$} \\
\hline Group 5 & $20.45(2.93)$ & 16.00 & 27.00 \\
\hline Protaper Next & & & \\
\hline
\end{tabular}

By the one way ANOVA, $F=35.385 ; p=0.000(p<0.05)$.

Groups with the same letter (a) was not significantly different at $\mathrm{p}>0.05$ by Tukey's Test. 
inflammatory reaction after the initiation of root canal treatment. When these factors are taken into account, extrusion of intracanal material plays a significant role in the overall success of endodontic treatment.

In a biofilm, cell densities are significantly higher than in planktonic culture. ${ }^{[3]}$ Therefore, most biofilm cells have higher levels of secondary metabolites, waste products and secreted factors when compared with planktonic bacteria. Moreover, biofilms have lower nutrient and oxygen limitation. ${ }^{[21]}$ Additionally, biofilms are known to express genes different from planktonic cells. They are much more metabolically active than planktonic cells in the stationary phase. Biofilms are also difficult to remove from root canals and serve as important factors in failed endodontic treatments. For these reasons, we used biofilms to assess apical extrusion similar to previous studies. ${ }^{[4,5]}$

Endodontic engine-driven NiTi instrumentation systems have recently been redesigned in an attempt to perform more efficient root canal treatments. One of these systems, K3XF, has been investigated in terms of debris extrusion. Garlapati, et al. ${ }^{[15]}$ evaluated the number of apically extruded bacteria during root canal preparation using 4 rotary instrumentation techniques., Although less bacterial extrusion was found in the K3 group, the maximum amount of extruded bacteria was determined with Mtwo. Furthermore, H K S, et al. ${ }^{[22]}$ evaluated the apical extrusion of intracanal debris during root canal instrumentation using hand instruments, ProTaper, K3, and LightSpeed LSX. They found no statistically significant difference among the tested NiTi instruments. In another study, Nagaveni, et al. ${ }^{[23]}$ evaluated the weight of debris and volume of irrigant extruded apically after endodontic instrumentation using ProTaper Universal, HeroShaper, $\mathrm{RaCe}$, and $\mathrm{K} 3$. All of the tested instrumentation systems caused measurable apical extrusion of debris and irrigants. HeroShaper, $\mathrm{K} 3$ and RaCe systems produced less extruded debris and irrigant than the ProTaper system. Madhusudhana, et al. ${ }^{[24]}$ assessed apical debris and irrigant extrusion using ProTaper, K3, Mtwo systems. All instrumentation techniques produced significant amount of extruded debris and irrigant. Moreover, no statistically significant differences were found between the ested NiTi systems. K3XF caused small amounts of bacteria to be extruded and no significant difference was noted among the K3XF and OSNG systems. This result may associated with configurational differences between $\mathrm{K} 3 \mathrm{XF}$ and OSNG like blades, flutes, helical angle and pitch shapes that provided a variable design along the cutting part. Although in the present study, there were a few variations such as the number of inoculated bacteria, ${ }^{[15]}$ the type of instrumentation systems used, ${ }^{[22,23]}$ and irrigation solu- tion, ${ }^{[24]}$ the results was showed similarity to the abovementioned studies. ${ }^{[15,22-24]}$

Recently, TFA has been examined in few studies in terms of extrusion. Capar, et al. ${ }^{[13]}$ compared the amount of apically extruded debris with ProTaper Universal, PTN, TFA and HyFlex. The TFA and PTN systems extruded significantly less debris than the ProTaper Universal and HyFlex systems. The current study examined and revealed biofilm extrusion during TFA instrumentation. Although, only the TFA systems was used with adaptive motion, a significant amount of biofilm extrusion was observed this group. The adaptive motion incorporates both reciprocating and rotational motion. Some studies indicated that; rotational motion was associated with less debris extrusion compared to reciprocating motion ${ }^{[25,26]}$ The greater amount of extrusion observed with TFA may be explained with the reciprocating component when compared with rotational motion systems such as K3XF, OSNG and PTN in present study.

Yeter, et al. ${ }^{[27]}$ compared the weight of apically extruded debris using $\mathrm{K}$-files, and the RS system. Both hand and rotary instrumentation resulted in extrusion of debris beyond the apical foramen. No significant difference was observed between $\mathrm{K}$-files and RS system. RS system has not been evaluated in terms of bacterial extrusion, so far. In the present study, RS file caused more bacterial extrusion compared to the other groups. This may be due to asymmetric triangular cross section with flutes, helical angle and pitch triple helix of RS. In the present study, OSNG caused less amount of bacterial extrusion than all other instrumentation systems. This result may be attributed to the variable, asymmetric and off-centered cross section resulting in an asymmetrical rotary motion. Inherited design provides the following advantages such as; reduced screw in-effect, reduced torsion, less resistance and stress along the length, minimal cyclic fatigue along the file, easy curvature negotiation, better apical control, and increased debris elimination. Moreover, Mittal, et al ${ }^{[28]}$ compared the amount of apically extruded bacteria with manual, ProTaper Universal and One Shape systems. They concluded that multi-file ProTaper Universal system extruded significantly more bacteria than single-file One Shape system. Similarly, according to the results of present study, singlefile system OSGN caused less bacterial extrusion compared to multi-file K3XF, PTN and RS systems, although there was no statistically significant difference between OSGN and K3XF. Another NiTi file that was evaluated by few researchers is PTN. Kirchhoff, et al. ${ }^{[29]}$ evaluated the amount of apically extruded debris in flat-oval root canal systems using different instrumentation systems. They observed no significant difference amongst the PTN, WO, and TFA. 
Capar, et al ${ }^{[13]}$ compared the amount of apically extruded debris with new endodontic rotary nickel-titanium instruments. PTN instrumentation systems were associated with less debris extrusion compared with other systems. Üstün, et al. ${ }^{[30]}$ evaluated the apical extrusion of debris associated with several root canal preparation systems. The Wave One system extruded less debris compared to the TFA and PTN systems. In the present study, a small amount of bacterial extrusion was noted with the PTN system. The offset rectangular mass and eccentric axis of rotation with swaggering motion of PTN may account for such a result. As a result, although PTN extruded less bacteria than RS and TFA, PTN produced more biofilm when compared with OSNG and K3XF.

\section{Conclusions}

All NiTi instrumentation systems were associated with apical extrusion of bacteria. OSNG and K3XF can be preferable as a safer instrument in terms of bacteria extrusion compared to tested other instruments.

\section{Acknowledgments}

The authors deny any conflicts of interest related to this study.

\section{References}

1. Seltzer S, Naidorf IJ. Flare-ups in endodontics: I. Etiological factors. J Endod 1985;11:472-8. Crossef

2. Seltzer S, Soltanoff W, Sinai I, Goldenberg A, Bender IB. Biologic aspects of endodontics. 3. Periapical tissue reactions to root canal instrumentation. Oral Surg Oral Med Oral Pathol 1968;26:694-705, Crosstef

3. Prigent-Combaret C, Vidal O, Dorel C, Lejeune P. Abiotic surface sensing and biofilm-dependent regulation of gene expression in Escherichia coli. J Bacteriol 1999;181:59936002.

4. Huth KC, Quirling M, Maier S, Kamereck K, Alkhayer M, Paschos E, et al. Effectiveness of ozone against endodontopathogenic microorganisms in a root canal biofilm model. Int Endod J 2009;42:3-13. Crossef

5. Estrela C, Sydney GB, Figueiredo JA, Estrela CR. Antibacterial efficacy of intracanal medicaments on bacterial biofilm: a critical review. J Appl Oral Sci 2009;17:1-7.

6. Martin $\mathrm{H}$, Cunningham WT. The effect of endosonic and hand manipulation on the amount of root canal material extruded. Oral Surg Oral Med Oral Pathol 1982;53:6113. Crossref

7. al-Omari MA, Dummer PM. Canal blockage and debris extrusion with eight preparation techniques. J Endod 1995;21:154-8. Crossref

8. Reddy SA, Hicks ML. Apical extrusion of debris using two hand and two rotary instrumentation techniques. J Endod 1998;24:180-3. Crossref

9. Ferraz CC, Gomes NV, Gomes BP, Zaia AA, Teixeira FB, Souza-Filho FJ. Apical extrusion of debris and irrigants using two hand and three engine-driven instrumentation techniques. Int Endod J 2001;34:354-8. Crossref

10. Tinaz AC, Alacam T, Uzun O, Maden M, Kayaoglu G. The effect of disruption of apical constriction on periapical extrusion. J Endod 2005;31:533-5. Crossref

11. Basrani B, Roth K, Sas G, Kishen A, Peters OA. Torsional profiles of new and used revo-s rotary instruments: an in vitro study. J Endod 2011;37:989-92. Crossref

12. Larsen CM, Watanabe I, Glickman GN, He J. Cyclic fatigue analysis of a new generation of nickel titanium rotary instruments. J Endod 2009;35:401-3. Crosstef

13. Capar ID, Ertas H, Ok E, Arslan H, Ertas ET. Comparative study of different novel nickel-titanium rotary systems for root canal preparation in severely curved root canals. J Endod 2014;40:852-6. Crossef

14. Gambarini G, Gerosa R, De Luca M, Garala M, Testarelli L. Mechanical properties of a new and improved nickeltitanium alloy for endodontic use: an evaluation of file flexibility. Oral Surg Oral Med Oral Pathol Oral Radiol Endod 2008;105:798-800. Crossef

15. Garlapati R, Venigalla BS, Patil JD, Raju R, Rammohan C. Quantitative evaluation of apical extrusion of intracanal bacteria using K3, Mtwo, RaCe and protaper rotary systems: An in vitro study. J Conserv Dent 2013;16:300-3.

16. Alapati SB, Brantley WA, Iijima M, Schricker SR, Nusstein JM, Li UM, et al. Micro-XRD and temperature-modulated DSC investigation of nickel-titanium rotary endodontic instruments. Dent Mater 2009;25:1221-9. Crossef

17. Zhou HM, Shen Y, Zheng W, Li L, Zheng YF, Haapasalo M. Mechanical properties of controlled memory and superelastic nickel-titanium wires used in the manufacture of rotary endodontic instruments. J Endod 2012;38:153540. Crossef

18. Huang X, Ling J, Wei X, Gu L. Quantitative evaluation of debris extruded apically by using ProTaper Universal Tulsa rotary system in endodontic retreatment. J Endod 2007;33:1102-5. Crossref

19. Er K, Sümer Z, Akpinar KE. Apical extrusion of intracanal bacteria following use of two engine-driven instrumentation techniques. Int Endod J 2005;38:871-6. Crossref

20. Kuştarci A, Akpinar KE, Sümer Z, Er K, Bek B. Apical extrusion of intracanal bacteria following use of various instrumentation techniques. Int Endod J 2008;41:1066-71.

21. Parsek MR, Greenberg EP. Sociomicrobiology: the connections between quorum sensing and biofilms. Trends Microbiol 2005;13:27-33. Crossref

22. H K S, T S S, Goel BR, T N N, Bhandi SH. Quantitative assessment of apical debris extrusion and intracanal debris in the apical third, using hand instrumentation and 
three rotary instrumentation systems. J Clin Diagn Res 2014;8:206-10.

23. Nagaveni SA, Balakoti KR, Smita K, Ratnakar P, Satish SV, Aravind T. Quantitative evaluation of apical extrusion of debris and irrigants using four rotary instrumentation systems: an in vitro study. J Contemp Dent Pract 2013;14:1065-9.

24. Madhusudhana K, Mathew VB, Reddy NM. Apical extrusion of debris and irrigants using hand and three rotary instrumentation systems - An in vitro study. Contemp Clin Dent 2010;1:234-6.

25. Bürklein S, Schäfer E. Apically extruded debris with reciprocating single-file and full-sequence rotary instrumentation systems. J Endod 2012;38:850-2. Crossref

26. Bürklein S, Benten S, Schäfer E. Quantitative evaluation of apically extruded debris with different single-file systems:
Reciproc, F360 and OneShape versus Mtwo. Int Endod J 2014;47:405-9. Crossref

27. Yeter KY, Evcil MS, Ayranci LB, Ersoy I. Weight of apically extruded debris following use of two canal instrumentation techniques and two designs of irrigation needles. Int Endod J 2013;46:795-9. Crossref

28. Mittal R, Singla MG, Garg A, Dhawan A. A Comparison of Apical Bacterial Extrusion in Manual, ProTaper Rotary, and One Shape Rotary Instrumentation Techniques. J Endod 2015;41:2040-4. Crossref

29. Kirchhoff AL, Fariniuk LF, Mello I. Apical extrusion of debris in flat-oval root canals after using different instrumentation systems. J Endod 2015;41:237-41. Crossref

30. Üstün Y, Çanakçi BC, Dinçer AN, Er O, Düzgün S. Evaluation of apically extruded debris associated with several Ni-Ti systems. Int Endod J 2015;48:701-4. Crossref 